\title{
Sources of Health Information, Technology Access, and Use Among Non-English-Speaking Immigrant Women: Descriptive Correlational Study
}

\author{
Steve Chae ${ }^{1 *}$, MSN, RN; Yoon-Jae Lee ${ }^{1 *}$, BSN, RN; Hae-Ra Han ${ }^{1,2^{*}}, \mathrm{PhD}, \mathrm{RN}, \mathrm{FAAN}$ \\ ${ }^{1}$ Johns Hopkins University School of Nursing, Baltimore, MD, United States \\ ${ }^{2}$ Johns Hopkins University Bloomberg School of Public Health, Baltimore, MD, United States \\ *all authors contributed equally
}

Corresponding Author:

Hae-Ra Han, PhD, RN, FAAN

Johns Hopkins University School of Nursing

525 N Wolfe St, Room 533

Baltimore, MD, 21205

United States

Phone: 13106142669

Email: hhan3@jhu.edu

\section{Abstract}

Background: As the world is becoming increasingly connected by the World Wide Web, the internet is becoming the main source of health information. With the novel COVID-19 pandemic, ubiquitous use of the internet has changed the daily lives of individuals, from working from home to seeking and meeting with health care providers through web-based sites. Such heavy reliance on internet-based technologies raises concerns regarding the accessibility of the internet for minority populations who are likely to already face barriers when seeking health information.

Objective: This study aims to examine the level of technology access and common modes of technology used by Korean American women and to investigate how key psychosocial determinants of health such as age, education, English proficiency, and health literacy are correlated with sources of health information used by Korean American women and by their use of the internet.

Methods: We used data from a subsample of Korean American women $(\mathrm{N}=157)$ who participated in a community-based randomized trial designed to test a health literacy-focused cancer screening intervention. In addition to descriptive statistics to summarize Korean American women's internet access and common modes of technology use, we conducted backward stepwise logistic regression analyses to substantiate the association between the psychosocial determinants of health and internet use.

Results: Approximately two-thirds (103/157, 65.6\%) of the sample had access to the internet, and nearly all had access to a mobile phone. The internet was the most commonly used channel to obtain health information 63\% (99/157), and 70\% (110/157) of the sample used text messaging. Nevertheless, only approximately $38.8 \%$ (40/103) of the sample were very confident in using the internet, and only $29.9 \%$ (47/157) were very confident in using text messaging. Multivariate analyses revealed that older age (>50 years) was associated with $79 \%$ lower odds of using the internet to seek health information (adjusted odds ratio [AOR] 0.21, 95\% CI 0.10-0.46). The higher health literacy group (19+ on Rapid Estimate of Adult Literacy in Medicine) had 56\% lower odds of using the internet to acquire health information (AOR 0.44, 95\% CI 1.13-11.18). Higher education (college+) was associated with both internet use (AOR 4.42, 95\% CI 1.88-9.21) and text messaging (AOR 3.42, 95\% CI 1.55-7.54). Finally, English proficiency was associated with text messaging (AOR 4.20, 95\% CI 1.44-12.24).

Conclusions: The differences in modes of technology access, use, and confidence by some of the key psychosocial determinants, as observed in our study sample, have important implications when health care teams develop dissemination plans.

(J Med Internet Res 2021;23(10):e29155) doi: 10.2196/29155

\section{KEYWORDS}

technology use; internet; text messaging; health literacy; English proficiency; immigrant; health disparities; Korean American; women; mobile phone 


\section{Introduction}

\section{Background}

The internet is a unique technology that is constantly developing and encompasses various forms of technologies, such as social media, e-communications, e-commerce, telecommunications, and telehealth. The internet is currently used as a platform that connects people, stores and shares information, and virtually provides health services [1]. Especially during the COVID-19 pandemic, with the suspension of many face-to-face medical and health care services, telehealth and telecommunication have been widely used to offset the loss of manpower within face-to-face medical services [2]. Furthermore, many forms of internet-based health technologies ease the daily lives of Americans by providing ways to self-manage their illnesses and conditions such as diabetes, physical activity, diet, weight loss, heart failure, and more [3]. These daily health technologies use combinations of already existing technologies that are updated with the current technology. For example, sphygmomanometer, weight scale, electrocardiogram recorder, and smartphone apps are combined to monitor heart failure with cost-saving benefits compared with telephone-based monitoring [4].

Despite the proven benefits and rapidly increasing, ubiquitous use of the internet and internet-based health technologies for all Americans, this rapid incline is exposing the health disparities and digital divide in underserved populations: racial and ethnic minorities, older adults, rural populations, lower-income groups, and populations with a lower educational background $[5,6]$. These underserved populations are more likely to have lower health literacy levels, lack health care coverage, lack provider availability, experience lower quality of care, and are more likely to face discrimination in general and in health care [7] They are also less likely to have adequate internet connectivity and are less likely to use the internet to seek health information $[5,8]$.

Asian racial or ethnic minorities are rapidly growing in the United States: $72 \%$ growth between 2000 and 2015 compared with $60 \%$ in Hispanic racial or ethnic minority populations and are currently projected to be the largest immigrant racial or ethnic group by 2055 , accounting for $38 \%$ of the immigrant population [9]. Overall, 97\% of English-speaking Asian Americans are estimated to use the internet compared with $85 \%$ of non-Hispanic Whites, $81 \%$ of Hispanics, and $78 \%$ of non-Hispanic Blacks [10]. However, the healthier and more affluent Asian American subgroups tend to be overrepresented in these reports. This tends to overcast the underserved Asian American subgroups: non-English-speaking, lower socioeconomic status, elderly, disabled, and unauthorized immigrant subgroups comprise more than 50 ethnic and 100 language groups [11]. Some of these smaller Asian ethnic and language groups live in poverty rates that are three times higher than the US average of $10.5 \%$, such as Hmong (28.3\%), Bhutanese (33.3\%), and Burmese (35\%) [9,12]. In addition, some subgroups, such as Koreans, culturally do not express their hardships or deficiencies to the public because they do not want to show their weakness-financially or socially [9].
According to the 2019 American Community Survey, Korean Americans are the fifth largest Asian population and represent one of the fastest growing ethnic groups in the United States [13]; 59\% of Korean Americans are first-generation immigrants, significantly higher than the $14 \%$ immigrant share among general Americans [14]. Research has revealed health disparities in the Korean American population. For example, Korean American women are 1.5 times more likely to die from cervical cancer than non-Hispanic White women, yet are nearly $20 \%$ less likely to receive triennial Papanicolaou tests $[15,16]$. Korean Americans are also more susceptible to acquiring hepatitis B virus than White Americans by 10-fold because of significant language barriers, limited health knowledge, financial issues, and poor access to care [17].

With their well-documented benefits, internet-based health technologies provide an opportunity to eliminate the health disparities experienced by traditionally underserved populations with limited resources and limited English proficiency, such as Korean Americans [5]. However, information addressing technology access and the use of the internet among Korean Americans is currently scarce. As health care professionals are rapidly adapting and expanding the use of the internet and technology, a better understanding of how Korean American women use the internet may help researchers and clinicians to implement and disseminate health programs to address health disparities in Korean American populations.

\section{Objective}

The purpose of this study was to understand the internet use among Korean American women. Specifically, we examined the level of internet access and the common modes of technology used by the target group of Korean American women. We also investigated how key social determinants of health, such as age, education, English proficiency, and health literacy, are associated with Korean American women's use of internet technology.

\section{Methods}

\section{Study Design and Sample}

This study used data obtained from a sample of Korean American women who participated in a community-based, cluster randomized controlled trial that was designed to test the efficacy of a community health worker-led health literacy-focused intervention program, including mammograms and Papanicolaou test screening, among Korean American women. Details regarding the study design and outcomes have been published elsewhere (NCT00857636) [18]. Briefly, trained community health workers from 23 ethnic churches (intervention=11 and waitlist control=12) in the Maryland-Washington metropolitan area recruited the study sample. Sample inclusion criteria included Korean American women aged 21-65 years who were overdue for either a mammogram (for women aged $\geq 40$ years) or Papanicolaou tests. Those with an acute or terminal condition (eg, cancer diagnosis or life expectancy of $<6$ months), psychiatric diagnosis, or other conditions that precluded participation in the study activities were excluded. A total of 560 eligible women were recruited and enrolled in the study (intervention, $\mathrm{n}=278$; control, $\mathrm{n}=282$ ) 
and completed the baseline assessment. Follow-up data were collected at 3 and 6 months from the start of the intervention. At 6-month follow-up, 527 women participated in the final data collection (intervention, $n=261$; control, $n=266$ ). For the women participating only in the intervention, a brief phone survey was conducted 1 year after the final data collection between 2013 and 2017. The main goal of this 1-year postsurvey was to examine the long-term effects of the study intervention on cancer screening behaviors and the intervention of women's dissemination of cancer screening knowledge to neighbors in the community (Multimedia Appendix 1). The postsurvey also included questions about access to and use of the internet. A total of 157 intervention women participated in the 1-year postsurvey (response rate $=60 \%$ ). For this analysis, we combined baseline data for key sociodemographic and 1-year postsurvey data for internet use.

\section{Procedures and Measures}

All study procedures were approved by the Johns Hopkins Medicine Institutional Review Board. The baseline questionnaire was administered face-to-face by trained bilingual research staff to assess participant characteristics. The baseline questionnaire included sociodemographic questions such as age in years, educational level, income comfortability, marital status, health insurance, and English proficiency. In addition, health literacy was measured using the Rapid Estimate of Adult Literacy in Medicine (REALM), a well-validated 66-item screening instrument that assesses an adult's ability to read common medical words and lay terms for body parts and illnesses [19]. Each correctly pronounced word was coded as 1 , with a total score ranging from 0 to 66. The REALM has been significantly correlated with other standardized reading tests. The REALM was validated in a Korean sample [20].

The 1-year postsurvey was completed through phone interviews by trained bilingual research assistants. Trained bilingual research assistants called the study participants in the intervention group who agreed to participate in a follow-up survey. Part of the postsurvey asked questions about the main sources of health information (eg, internet, television [TV], radio, newspaper, book, or magazine) and access to the internet (with access location) and mobile phones. For those who reported the internet as the main source of health information, additional questions were asked about the frequency of internet use and types of health information sought. Similarly, for those who reported having access to mobile phones, the frequency of use of text messaging was asked. Finally, the level of confidence in using the internet and text messaging was assessed for those who indicated access to these technologies. Each phone interview lasted, on average, approximately 10 minutes.

\section{Data Analysis}

We used descriptive statistics such as means, SDs, frequencies, and percentages to summarize the sample characteristics. We conducted a series of backward stepwise logistic regression analyses to examine the association between the key social determinants of health (age, education, English proficiency, and health literacy), sources of health information, use of internet technology, and confidence in using technologies. Age, education, and English proficiency were categorized as young and old ( $<50$ years vs $\geq 50$ ), low and high education (less than college vs college or more), and limited and proficient English (none, little, and well vs fluent). More than $80 \%$ of the analysis sample scored zero on the REALM; hence, instead of using the suggested cutoff of 60 to represent adequate health literacy (ie, high school reading level), we used a cutoff of 18 to categorize the sample as low versus high health literacy groups. The cutoff of 18 on the REALM indicates a reading level of third grade and below, where people will not be able to read most low-literacy materials and may require repetitive oral instructions or written materials composed of illustrations or audiotapes or videotapes [19]. All statistical significance was set at $P<.05$.

\section{Results}

\section{Sample Characteristics}

Table 1 summarizes the sample characteristics. The analysis sample was mostly middle-aged (mean age 46.3, SD 8.2 years) and married (133/157, 84.7\%) women. More than half (100/157, $63.7 \%$ ) received college or more education, but only 1 in 5 $(33 / 157,21 \%)$ said they felt comfortable with their income level. Slightly more than one-third $(55 / 157,35 \%)$ of study participants indicated at baseline that they had health insurance and a primary care provider $(53 / 157,33.7 \%)$. The majority of the sample had limited English proficiency; only $12.1 \%(19 / 157)$ reported being fluent in English. Similarly, more than three-fourths $(134 / 157,85.4 \%)$ scored $\leq 18$ on the REALM, indicating a reading level of third grade or lower. 
Table 1. Sample characteristics (N=157).

\begin{tabular}{|c|c|}
\hline Characteristics & Values \\
\hline Age (years; range 24-64), mean (SD) & $46.3(8.2)$ \\
\hline$<50, \mathrm{n}(\%)$ & $96(61.1)$ \\
\hline$\geq 50, \mathrm{n}(\%)$ & $61(38.9)$ \\
\hline Married, n (\%) & $133(84.7)$ \\
\hline Education (years; range 8-22), mean (SD) & $14.7(2.5)$ \\
\hline Less than college (12 years), n (\%) & $57(36.4)$ \\
\hline College and more (13 years), $\mathrm{n}(\%)$ & $100(63.7)$ \\
\hline \multicolumn{2}{|l|}{ Income comfortability, $\mathbf{n}(\%)$} \\
\hline Difficult and very difficult & $69(43.9)$ \\
\hline Okay & $55(35.0)$ \\
\hline Comfortable and very comfortable & $33(21.0)$ \\
\hline Have health insurance, $\mathrm{n}(\%)$ & $55(35.0)$ \\
\hline Have primary care provider, $\mathrm{n}(\%)$ & $53(33.8)$ \\
\hline \multicolumn{2}{|l|}{ English proficiency, n (\%) } \\
\hline None, little and well & $138(87.9)$ \\
\hline Fluent & $19(12.1)$ \\
\hline Health literacy (range 0-66), mean (SD) & $7.0(17.0)$ \\
\hline Third grade reading level or less, $\mathrm{n}(\%)$ & $134(85.4)$ \\
\hline More than third grade reading level, $\mathrm{n}(\%)$ & $23(14.6)$ \\
\hline
\end{tabular}

\section{Technology Accessibility, Usability, and Confidence}

Table 2 shows the technology accessibility, usability, and confidence of Korean American women. The most commonly used method for obtaining health information was the internet $(99 / 157,63 \%)$. Of those who indicated the internet as the main source of health information, the main types of health information they searched for were disease (64/99, 65\%), followed by alternative medicine $(26 / 99,26 \%)$ and health supplements $(21 / 99,21 \%)$; the majority $(65 / 99,66 \%)$ indicated that they searched on average 1-2 times or less per month. Approximately two-thirds (103/157, 65.6\%) of the study sample indicated that they had access to the internet; most of them $(101 / 103,98.1 \%)$ had internet access at home. In addition, nearly all $(153 / 157,97.5 \%)$ participants reported that they had access to a mobile phone; $70.1 \%(110 / 157)$ used text messaging. Nevertheless, only $39 \%$ (40/103) were very confident in using the internet; $30 \%(47 / 157)$ were very confident in using text messaging. 
Table 2. Accessibility and use of technology $(\mathrm{N}=157)$.

\begin{tabular}{|c|c|}
\hline Characteristics & Values, $\mathrm{n}(\%)$ \\
\hline \multicolumn{2}{|l|}{ Sources of health information ${ }^{a}$} \\
\hline Internet & $99(63.1)$ \\
\hline Newspaper, magazine, and book & $58(36.9)$ \\
\hline Television and radio & $42(26.8)$ \\
\hline Friend, family, and acquaintances & $26(16.6)$ \\
\hline Physician & $3(1.9)$ \\
\hline Community & $3(1.9)$ \\
\hline \multicolumn{2}{|c|}{ Types of health information sought on the internet ${ }^{a, b}$} \\
\hline Disease & $64(64.6)$ \\
\hline Alternative medicine & $26(26.3)$ \\
\hline Health supplement & $21(21.2)$ \\
\hline Medication & $13(13.1)$ \\
\hline Hospital and physician & $8(8.1)$ \\
\hline General health & $2(2.0)$ \\
\hline Missing & $21(21.2)$ \\
\hline \multicolumn{2}{|c|}{ Frequency of internet use for health information ${ }^{b}$} \\
\hline 1-2 times or less per month & $65(65.7)$ \\
\hline 1-2 times per week & $11(11.1)$ \\
\hline$\geq 3$ times per week & $8(8.1)$ \\
\hline Missing & $15(15.1)$ \\
\hline Have internet access & $103(65.6)$ \\
\hline \multicolumn{2}{|l|}{ Location of access ${ }^{c}$} \\
\hline Home & $101(98.1)$ \\
\hline Work & $15(14.6)$ \\
\hline Public library & $5(4.9)$ \\
\hline School & $1(1)$ \\
\hline Have mobile access & $153(97.5)$ \\
\hline Use text messaging & $110(70.1)$ \\
\hline \multicolumn{2}{|l|}{ Confidence with internet use ${ }^{c}$} \\
\hline Not at all, fairly, and somewhat & $63(61.1)$ \\
\hline Very confident & $40(38.9)$ \\
\hline \multicolumn{2}{|l|}{ Confidence with text messaging } \\
\hline Not at all, fairly, and somewhat & $87(55.4)$ \\
\hline Very confident & $47(29.9)$ \\
\hline Missing & $23(14.6)$ \\
\hline
\end{tabular}

${ }^{\mathrm{a}}$ Multiple choice.

${ }^{b}$ Women who used the internet to obtain health information only ( $\mathrm{n}=99$ ).

${ }^{\mathrm{c}}$ Women who had access to the internet only $(\mathrm{n}=103)$. 


\section{Relationship Among Social Determinants of Health, Sources of Health Information, Technology Use, and Confidence}

Multivariate analyses revealed that older age was associated with approximately $79 \%$ lower odds of using the internet as the main source of health information (adjusted odds ratio [AOR] $0.213,95 \%$ CI $0.100-0.455$ ) but had at least 2.4 times higher odds of using print media (eg, books and magazines) to obtain health information (AOR 2.403, 95\% CI 1.166-4.950). The high health literacy group had 56\% lower odds (AOR 0.440, 95\% CI 1.134-11.182) of using the internet to acquire health information but more than 1.5 times higher odds (AOR 1.535, 95\% CI 1.004-6.400) of using TV and radio. When these variables were examined compared with technology use and confidence, educational level was significantly associated with both internet use (AOR 4.419, 95\% CI 1.870-9.205) and text messaging (AOR 3.417, 95\% CI 1.549-7.540), with high education favoring the use of both technologies. Although no variables were associated with confidence in using the internet, English proficiency was associated with more than four times higher odds of confidence in using text messaging (AOR 4.198, 95\% CI 1.439-12.244; Table 3).

Table 3. Multiple logistic regression analysis to explain sources of health information, technology use, and confidence ${ }^{\mathrm{a}}$.

\begin{tabular}{|c|c|c|c|c|}
\hline \multirow[t]{2}{*}{ Outcome } & \multicolumn{4}{|c|}{ Social determinants of health, adjusted odds ratio $(95 \% \mathrm{CI})$} \\
\hline & Age & English proficiency & Education & Health literacy \\
\hline \multicolumn{5}{|c|}{ Main source of health information } \\
\hline Internet & $0.213(0.100-0.455)$ & $\mathrm{N} / \mathrm{A}^{\mathrm{b}}$ & N/A & $0.440(1.134-11.182)$ \\
\hline Print & $2.403(1.166-4.950)$ & N/A & N/A & N/A \\
\hline Television and radio & N/A & N/A & N/A & $1.535(1.004-6.400)$ \\
\hline \multicolumn{5}{|l|}{ Use of technology } \\
\hline Internet & N/A & N/A & $4.419(1.870-9.205)$ & N/A \\
\hline Text messaging & N/A & N/A & $3.417(1.549-7.540)$ & N/A \\
\hline \multicolumn{5}{|c|}{ Confidence in using technology } \\
\hline Internet & N/A & $4.198(1.439-12.244)$ & N/A & N/A \\
\hline Text messaging & N/A & N/A & N/A & N/A \\
\hline
\end{tabular}

${ }^{\text {a }}$ Variables were added if the $P$ value was less than .05 . The adjusted odds ratio $(95 \% \mathrm{CI})$ is displayed. The different groups were as follows: younger age ( $<50$ years), limited English proficiency (less than fluent English), low education (less than college), and low health literacy ( $\leq 18$ on the Rapid Estimate of Adult Literacy in Medicine).

${ }^{\mathrm{b}} \mathrm{N} / \mathrm{A}$ : not applicable.

\section{Discussion}

\section{Principal Findings}

We found that only approximately two-thirds of our study sample had internet access. However, the internet was the most popular source of health information used by Korean American women in this study. We also found that although nearly all study participants $(153 / 157,97.4 \%)$ had access to a mobile phone, slightly more than two-thirds $(110 / 157,70 \%)$ of them used text messaging. The Korean American women in the study had overall low levels of confidence in using the internet and text messaging. Older women, lower education, and limited English proficiency were associated with less use of these technologies. This is one of the first studies to comprehensively examine the common modes of technology and to investigate how key social determinants of health are associated with technology use in one of the fastest growing yet understudied ethnic groups in the nation (ie, Korean American) [21].

The level of home-based internet access among our study sample of Korean American women was comparable with that in Black populations $(66 \%)$ but lower than that in the general US population (73\%) or White populations (79\%) and higher than that in Hispanic (61\%) populations [5]. Relying on the internet to seek health information may have been due in part to the finding that Korean Americans represent one of the most uninsured ethnic groups in the nation. For example, in a survey of 498 patients from primary care clinics mainly serving Hispanic and Black patients, Gutierrez et al [21] revealed that the primary source of health information most commonly reported was their health care professionals, followed by various forms of media, such as news, radio, or books. The internet was used less frequently $(<25 \%)$. In our study sample, only approximately one-third of women had health insurance (35\%) and reported having a primary care provider $(34 \%)$. For individuals with limited access to care, the internet may serve as a key resource for health information. As the internet plays an increasingly important role in health information access, it is important to identify strategies to promote and control the quality of health information posted on the internet. For example, a recent systematic review yielded three criteria that are most important in evaluating web-based health information: trustworthiness, expertise, and objectivity [22]. These indicators can be used to guide those who develop web-based health information.

Age was significantly associated with the sources of health information used by Korean American women in this study. 
Specifically, older age ( $\geq 50$ years) was associated with an approximately $80 \%$ lower likelihood of using the internet but more than two times higher likelihood of using print media as the main source of health information. Using data from the 2011-2014 Health Information National Trends Survey (58\% female and $70 \%$ White with mean age 54 years), Jacobs et al [23] reported that younger US populations were more likely to use web-based sources to seek health information compared with older populations. In this study, the older population with less internet proficiency was more likely to use health care professionals as a source of health information [23]. Taken together, our findings suggest the importance of satisfying health information-seeking behavior with appropriate dissemination approaches based on the characteristics of the target population.

Korean American women with higher education (college or more) were four times more likely to use the internet and three times more likely to use text messaging than women with less than a college-level education. The ability to use the internet and text messaging may be attributable to multiple factors such as generation gaps (eg, younger generations being exposed to digital technologies early on in their life), regularized use, and required higher reading levels for many publicly available websites. In particular, people with higher education are more likely to be easily adapted to use new technologies [24,25]. Korean American women with higher education might have learned to use the internet to seek information during years of education and used text messaging for social interactions and group projects. The national guideline states that health information on public websites should be written at a lower than eighth grade reading level [26,27]. Nevertheless, evidence suggests that the health information found on the web is above a grade 10 level or even 12th [28,29]. Most Korean American women in our study had an average reading level of third grade and lower on REALM, indicating a significant barrier to finding adequate health information on the web. Future efforts should focus on the development of plain language health information that is accessible and understandable to wider audiences, including recent immigrants with limited health literacy, such as Korean Americans.

We found that high health literacy was associated with a lower likelihood of using the internet but a higher likelihood of using $\mathrm{TV}$ and radio as the main source of health information. This finding conflicts with a study ( $\mathrm{N}=498,62 \%$ Hispanic) in which patients with limited health literacy had lower odds of seeking health information on the web after controlling for age, sex, and race and ethnicity [21]. It may be that Korean American women might have lacked the necessary skills to use health information on the internet. Overall, our study sample had very low health literacy, with $85 \%$ of participants being lower than the third-grade level. In addition, nearly 9 of 10 women (88\%) had limited English proficiency, a risk factor for low health literacy [30]. In fact, confidence in using the internet was more than four times higher among women with higher English proficiency in the study. The US Department of Health and Human Services' Healthy People 2020 published a report that states an upward trend of access to the internet in the general population, from $69 \%$ in 2007 to $81 \%$ in 2017 [31]. However, the proportion of web-based health information seekers who report that they can easily access health information decreased from $41 \%$ in 2008 to $38 \%$ in 2017 [31]. The findings suggest that having access to the internet does not necessarily mean that health information seekers have the skills and resources to adequately use the information obtained from the internet [32]. To collectively provide a wide range of health information to the general public, health information published on the web not only needs to be accurate and reliable in English and Spanish but also lower-grade English reading levels and diverse languages. As the US is projected to be a minority-majority country as early as 2045, it is particularly important to provide lower English reading levels and accurately translate health information [33].

Despite nearly every woman in our sample indicating access to a mobile phone, only $70 \%$ of those reported ever using text messaging, and only $30 \%$ were very confident. More than 9 of $10(97 \%)$ US adults use text messaging as the most frequently and widely used feature of smartphones [34]. Text messaging is an increasingly popular way of getting connected to the health care system for appointment alerts, information sharing, and methods for quick communication to question and answer between health care providers and patients. As studies show higher efficiency and result through text messaging for health care $[35,36]$, it is important to understand the reasons why Korean American women face difficulties in using text messaging features. Ladley et al [37] found that the use of text messaging to disseminate health information to infant caregivers with low health literacy improved information retention and resulted in fewer visits to the emergency department during the first year. The use of text messaging also benefits health care providers, as it offers advantages such as time management [38]. Active smartphone use may be a gateway for telehealth communications and web-based patient portals such as MyChart, which provide reliable sources of health information. Currently, digital technology health resources are primarily used by the highly educated White population and are often out of reach for those with less than high school education and lower English proficiency $[39,40]$. These underserved populations are likely to face barriers in accessing health care similar to MyChart because of external factors such as low health literacy and low technology proficiency or lack of access to the internet or devices to access web-based patient portals [40,41]. According to a recent review of technology use among underserved populations, having a proxy person to provide support helped to increase health technology uptake [32]. Future research should explore whether and how the availability of social resources to impart knowledge and skills can serve as a facilitator of digital technology use for health information in underserved populations.

\section{Limitations}

Our study limitations include a lack of generalizability of the study findings beyond the targeted sample. Women in the study were recruited from ethnic churches in one geographical area (Maryland-Washington metropolitan area). People in urban areas have more access to the internet than those in rural areas (97\% vs 65\%) [42]. Nevertheless, most Korean Americans reside in metropolitan areas (eg, Los Angeles, New York, and Washington, DC) [43]. In addition, we did not specify the use of social media as part of the postintervention survey, mainly 
focusing on some of the most common sources of information used in our study sample. However, the literature indicates that certain cultural and age groups (eg, Hispanic women aged between 45 and 55 years) use social media frequently, especially when a message is centered on familism [44]. This was a secondary analysis of data that were already collected for its parent study and were pulled only from the intervention group of its parent study sample. For the purposes of the parent study, participants completed a sociodemographic survey about 1.5 years before the internet use survey. However, we do not believe that any significant change might have occurred in the psychosocial determinants of health we examined (ie, age, education, English proficiency, and health literacy) in relation to technology use.

\section{Conclusions}

As the use of digital technology is ubiquitous in our daily lives with better health outcomes, it is important to allow all populations to use these technological advances to narrow the gap between health inequality. Although working with ethnic minority populations, particularly recent immigrants, it is important to understand the role of social determinants of health in relation to the types of technologies being used, how they are used, and their level of confidence in using the technologies. Such specific information may help provide effective strategies for optimal health information dissemination to engage underserved populations, such as Korean American women.
Future research should address barriers to and facilitators of using digital technologies, health information, and health care. In addition, given that people with limited access to health care, such as Korean Americans, are not likely to obtain health information from a health provider, diverse health information dissemination strategies beyond web-based information (eg, using friends and family as main sources of health information) should be considered and tested for its efficacy [45]. The Plain Writing Act of 2010 stipulates that the government-issued documents to the public be written clearly with the audiences' recommended reading level $[46,47]$. This act can be expanded to not only federally supported agencies but also all agencies subsidized by federal and state governments and include set guidelines of all documents disseminated be written with a readability score of eighth grade and lower in accordance with the National Institute of Health and American Medical Association's readability recommendations $[48,49]$. The rapid evolution of technology from word of mouth to telephones, radio, and TV and then to the internet and smartphones are differentiating the methods of obtaining health information and health care seeking behavior. The differences in the modes of obtaining health information in younger and older persons, as observed in our study sample, have important implications when health care teams develop dissemination plans. Having multiple modes such as paper, text message, and web-based along with dissemination with respect to age groups may lead to more successful health information delivery.

\section{Acknowledgments}

This study was supported, in part, by a grant from the National Cancer Institute (R01CA129060). Additional funding was received from the National Center for Advancing Translational Sciences (UL1TR003098), the National Institute of Nursing Research (P30NR018093), and the National Institute on Aging (R01AG062649). The funding sources had no role in the design and conduct of the study; collection, management, analysis, and interpretation of the data; preparation, review, or approval of the manuscript; and the decision to submit the manuscript for publication. The authors are grateful to all Korean American women and community health workers who participated in this study and to the research staff for their assistance with data collection.

\section{Authors' Contributions}

All authors approved the final version of the manuscript. HRH originated the study and led to writing. SC and YJL contributed to the development of the study concept and design. SC, YJL, and HRH contributed to the analysis and interpretation of the data. SC drafted the manuscript, and all authors contributed to the critical revision of the manuscript. HRH also supervised the study.

\section{Conflicts of Interest}

None declared.

\section{Multimedia Appendix 1}

"Obtaining Health Information" section of the postsurvey. [DOCX File, 15 KB-Multimedia Appendix 1]

\section{References}

1. Gordon NP, Crouch E. Digital information technology use and patient preferences for internet-based health education modalities: cross-sectional survey study of middle-aged and older adults with chronic health conditions. JMIR Aging 2019 Apr 04;2(1):e12243 [FREE Full text] [doi: 10.2196/12243] [Medline: 31518291]

2. Calton B, Abedini N, Fratkin M. Telemedicine in the time of coronavirus. J Pain Symptom Manage 2020 Jul;60(1):12-14 [FREE Full text] [doi: 10.1016/j.jpainsymman.2020.03.019] [Medline: $\underline{32240756]}$

3. Delva S, Mendez KJ, Cajita M, Koirala B, Shan R, Wongvibulsin S, et al. Efficacy of mobile health for self-management of cardiometabolic risk factors: a theory-guided systematic review. J Cardiovasc Nurs 2021;36(1):34-55 [FREE Full text] [doi: 10.1097/JCN.0000000000000659] [Medline: 32040072] 
4. Cajita MI, Gleason KT, Han H. A systematic review of mHealth-based heart failure interventions. J Cardiovasc Nurs 2016;31(3):10-22 [FREE Full text] [doi: 10.1097/JCN.0000000000000305] [Medline: 26544175]

5. Internet/broadband fact sheet. Pew Research Center. URL: https://www.pewresearch.org/internet/fact-sheet/internet-broadband [accessed 2021-03-10]

6. Lewis J. Internet access and racial/ethnic disparities in using internet health resources. U.S. Census Bureau. URL: https:/ /www.census.gov/content/dam/Census/library/working-papers/2017/demo/SEHSD-WP2017-31paper.pdf [accessed 2020-03-11]

7. Ndugga N, Artiga S. Disparities in health and health care: 5 key questions and answers. Kaiser Family Foundation. URL: https://www.kff.org/disparities-policy/issue-brief/disparities-in-health-and-health-care-five-key-questions-and-answers/ [accessed 2020-03-11]

8. Anderson M, Kumar M. Digital divide persists even as lower-income Americans make gains in tech adoption. Urbanism Next. URL: https://www.urbanismnext.org/resources/digital-divide-persists-even-as-lower-income-americansmake-gains-in-tech-adoption [accessed 2020-03-11]

9. Key facts about Asian Americans, a diverse and growing population. Pew Research Center. URL: https://www. pewresearch.org/fact-tank/2021/04/29/key-facts-about-asian-americans/ [accessed 2021-03-10]

10. Perrin A, Duggan M. Americans' internet access: 2000-2015. Pew Research Center. URL: https://www.pewresearch.org/ internet/2015/06/26/americans-internet-access-2000-2015/ [accessed 2021-03-10]

11. The rise of Asian Americans. Pew Research Center. URL: https://www.pewsocialtrends.org/2012/06/19/ the-rise-of-asian-americans [accessed 2021-03-10]

12. Income and poverty in the United States: 2019. U.S. Census Bureau. URL: https://www.census.gov/content/dam/Census/ library/publications/2020/demo/p60-270.pdf [accessed 2021-03-10]

13. 2019: ACS 5-Year estimates data profiles. U.S. Census Bureau. URL: https://data.census.gov/cedsci/ table?q=United\%20States\&g=0100000US\&tid=ACSDP5Y2019.DP05 [accessed 2021-03-10]

14. Budiman A, Ruiz N. Key facts about Asian origin groups in the U.S. Pew Research Center. URL: https://www. pewresearch.org/fact-tank/2021/04/29/key-facts-about-asian-origin-groups-in-the-u-s/ [accessed 2021-06-17]

15. Chawla N, Breen N, Liu B, Lee R, Kagawa-Singer M. Asian American women in California: a pooled analysis of predictors for breast and cervical cancer screening. Am J Public Health 2015 Feb;105(2):98-109. [doi: 10.2105/AJPH.2014.302250] [Medline: 25521898]

16. Miller JW, King JB, Joseph DA, Richardson LC, Centers for Disease Control and Prevention (CDC). Breast cancer screening among adult women--Behavioral Risk Factor Surveillance System, United States, 2010. MMWR Suppl 2012 Jun 15;61(2):46-50. [Medline: 22695463]

17. Hyun CS, Kim S, Kang SY, Jung S, Lee S. Chronic hepatitis B in Korean Americans: decreased prevalence and poor linkage to care. BMC Infect Dis 2016 Aug 15;16(1):415 [FREE Full text] [doi: 10.1186/s12879-016-1732-7] [Medline: 27526685]

18. Han H, Song Y, Kim M, Hedlin HK, Kim K, Ben Lee H, et al. Breast and cervical cancer screening literacy among korean american women: a community health worker-led intervention. Am J Public Health 2017 Jan;107(1):159-165. [doi: 10.2105/AJPH.2016.303522] [Medline: 27854539]

19. Davis TC, Long SW, Jackson RH, Mayeaux EJ, George RB, Murphy PW, et al. Rapid estimate of adult literacy in medicine: a shortened screening instrument. Fam Med 1993 Jun;25(6):391-395. [Medline: $\underline{\text { 8349060] }}$

20. Han H, Kim J, Kim MT, Kim KB. Measuring health literacy among immigrants with a phonetic primary language: a case of Korean American women. J Immigr Minor Health 2011 Apr;13(2):253-259 [FREE Full text] [doi: 10.1007/s10903-010-9366-0] [Medline: 20585985]

21. Gutierrez N, Kindratt TB, Pagels P, Foster B, Gimpel NE. Health literacy, health information seeking behaviors and internet use among patients attending a private and public clinic in the same geographic area. J Community Health 2014 Feb;39(1):83-89. [doi: 10.1007/s10900-013-9742-5] [Medline: 23900880]

22. Sun Y, Zhang Y, Gwizdka J, Trace CB. Consumer evaluation of the quality of online health information: systematic literature review of relevant criteria and indicators. J Med Internet Res 2019 May 02;21(5):e12522 [FREE Full text] [doi: 10.2196/12522] [Medline: 31045507$]$

23. Jacobs W, Amuta AO, Jeon KC. Health information seeking in the digital age: An analysis of health information seeking behavior among US adults. Cog Soc Sci 2017 Mar 13;3(1):1302785. [doi: 10.1080/23311886.2017.1302785]

24. Alexander B. Higher education, digital divides, and a Balkanized internet. EDUCAUSE Review. URL: https://er.educause.edu/ -/media/files/articles/2017/10/erm17612.pdf [accessed 2021-03-10]

25. Berner J, Rennemark M, Jogréus C, Anderberg P, Sköldunger A, Wahlberg M, et al. Factors influencing Internet usage in older adults (65 years and above) living in rural and urban Sweden. Health Informatics J 2015 Sep;21(3):237-249 [FREE Full text] [doi: 10.1177/1460458214521226] [Medline: 24567416]

26. Eltorai AE, Ghanian S, Adams CA, Born CT, Daniels AH. Readability of patient education materials on the American association for surgery of trauma website. Arch Trauma Res 2014 Jun 30;3(2):e18161 [FREE Full text] [doi: 10.5812/atr.18161] [Medline: 25147778]

27. Hutchinson N, Baird GL, Garg M. Examining the reading level of internet medical information for common internal medicine diagnoses. Am J Med 2016 Jun;129(6):637-639. [doi: 10.1016/j.amjmed.2016.01.008] [Medline: 26829438] 
28. Cajita MI, Rodney T, Xu J, Hladek M, Han H. Quality and health literacy demand of online heart failure information. J Cardiovasc Nurs 2017;32(2):156-164 [FREE Full text] [doi: 10.1097/JCN.0000000000000324] [Medline: 26938508]

29. Mishra V, Dexter JP. Comparison of readability of official public health information about COVID-19 on websites of international agencies and the governments of 15 countries. JAMA Netw Open 2020 Aug 03;3(8):e2018033 [FREE Full text] [doi: 10.1001/jamanetworkopen.2020.18033] [Medline: $\underline{32809028}$ ]

30. Sentell T, Braun KL. Low health literacy, limited English proficiency, and health status in Asians, Latinos, and other racial/ethnic groups in California. J Health Commun 2012;17 Suppl 3:82-99 [FREE Full text] [doi: 10.1080/10810730.2012.712621] [Medline: 23030563]

31. Health communication and health information technology data details. Office of Disease Prevention and Health Promotion. URL: https://www.healthypeople.gov/node/3508/data-details [accessed 2021-03-10]

32. Huh J, Koola J, Contreras A, Castillo A, Ruiz M, Tedone K, et al. Consumer health informatics adoption among underserved populations: thinking beyond the digital divide. Yearb Med Inform 2018 Aug;27(1):146-155 [FREE Full text] [doi: 10.1055/s-0038-1641217] [Medline: 30157518]

33. The US will become "minority white" in 2045, census projects. Brookings. URL: https://www.brookings.edu/blog/the-avenue/ 2018/03/14/the-us-will-become-minority-white-in-2045-census-projects/ [accessed 2021-03-10]

34. U.S. smartphone use in 2015. Pew Research Center. URL: https://www.pewresearch.org/internet/wp-content/uploads/sites/ 9/2015/03/PI Smartphones 0401151.pdf [accessed 2021-03-10]

35. Azulay R, Valinsky L, Hershkowitz F, Magnezi R. Repeated automated mobile text messaging reminders for follow-up of positive fecal occult blood tests: randomized controlled trial. JMIR Mhealth Uhealth 2019 Feb 05;7(2):e11114 [FREE Full text] [doi: 10.2196/11114] [Medline: $\underline{\text { 30720439] }}$

36. Ershad Sarabi R, Sadoughi F, Jamshidi Orak R, Bahaadinbeigy K. The effectiveness of mobile phone text messaging in improving medication adherence for patients with chronic diseases: a systematic review. Iran Red Crescent Med J 2016 May;18(5):e25183 [FREE Full text] [doi: 10.5812/ircmj.25183] [Medline: 27437126]

37. Ladley A, Broom M, Arthur J. Update on the evaluation of text messaging as an educational method to improve health care utilization. Acad Pediatr 2020;20(7):889-890. [doi: 10.1016/j.acap.2020.04.004] [Medline: 32302755]

38. Leahy D, Lyons A, Dahm M, Quinlan D, Bradley C. Use of text messaging in general practice: a mixed methods investigation on GPs' and patients' views. Br J Gen Pract 2017 Nov;67(664):744-750 [FREE Full text] [doi: 10.3399/bjgp17X693065] [Medline: 28947620]

39. Genes N, Violante S, Cetrangol C, Rogers L, Schadt EE, Chan YY. From smartphone to EHR: a case report on integrating patient-generated health data. NPJ Digit Med 2018;1:23 [FREE Full text] [doi: 10.1038/s41746-018-0030-8] [Medline: 31304305]

40. Han H, Gleason KT, Sun C, Miller HN, Kang SJ, Chow S, et al. Using patient portals to improve patient outcomes: systematic review. JMIR Hum Factors 2019 Dec 19;6(4):e15038 [FREE Full text] [doi: 10.2196/15038] [Medline: $\underline{31855187]}$

41. Bloom PP, Marx M, Wang TJ, Green B, Ha J, Bay C, et al. Attitudes towards digital health tools for outpatient cirrhosis management in patients with decompensated cirrhosis. BMJ Innov 2020 Jan 14;6(1):18-25. [doi: 10.1136/bmjinnov-2019-000369]

42. Homework gap and connectivity divide. Federal Communications Commission. URL: https://www.fcc.gov/about-fcc/ fcc-initiatives/bridging-digital-divide-all-americans [accessed 2021-03-10]

43. Top 10 U.S. metropolitan areas by Korean population, 2015. Pew Research Center. 2017. URL: https://www.pewresearch.org/ social-trends/chart/top-10-u-s-metropolitan-areas-by-korean-population/ [accessed 2021-03-10]

44. Blanco LR, Rodriguez LM. Delivering information about retirement saving among Hispanic women: two Facebook experiments. Behav Public Policy 2020 Nov;4(3):343-369 [FREE Full text] [doi: 10.1017/bpp.2018.33] [Medline: 34084943]

45. Cudjoe J, Budhathoki C, Roter D, Gallo JJ, Sharps P, Han H. Exploring health literacy and the correlates of pap testing among African immigrant women: findings from the Afropap study. J Cancer Educ 2021 Jun;36(3):441-451. [doi: 10.1007/s13187-020-01755-9] [Medline: 32410109]

46. Plain Writing Act of 2010. Digital.gov. URL: https://digital.gov/resources/plain-writing-act-of-2010/ [accessed 2021-08-12]

47. Federal plain language guidelines. plainlanguage.gov. URL: https://www.plainlanguage.gov/guidelines/ [accessed 2021-06-15]

48. Weiss B. Health literacy and patient safety: help patients understand. American Medical Association Foundation. 2007. URL: http://www.partnershiphp.org/Providers/HealthServices/Documents/Health\%20Education/CandLToolKit/ 2\%20Manual\%20for\%20Clinicians.pdf [accessed 2021-08-12]

49. Clear \& Simple: Clear Communication. National Institutes of Health. 2018. URL: https://www.nih.gov/institutes-nih/ nih-office-director/office-communications-public-liaison/clear-communication/clear-simple [accessed 2021-05-26]

\section{Abbreviations}

AOR: adjusted odds ratio

REALM: Rapid Estimate of Adult Literacy in Medicine

TV: television 
Edited by R Kukafka; submitted 28.03.21; peer-reviewed by MA Bahrami, H Moon; comments to author 13.05.21; revised version received 23.06.21; accepted 05.07.21; published 29.10.21

Please cite as:

Chae S, Lee YJ, Han HR

Sources of Health Information, Technology Access, and Use Among Non-English-Speaking Immigrant Women: Descriptive Correlational Study

J Med Internet Res 2021;23(10):e29155

URL: https://www.jmir.org/2021/10/e29155

doi: $\underline{10.2196 / 29155}$

PMID:

(C) Steve Chae, Yoon-Jae Lee, Hae-Ra Han. Originally published in the Journal of Medical Internet Research (https://www.jmir.org), 29.10.2021. This is an open-access article distributed under the terms of the Creative Commons Attribution License (https://creativecommons.org/licenses/by/4.0/), which permits unrestricted use, distribution, and reproduction in any medium, provided the original work, first published in the Journal of Medical Internet Research, is properly cited. The complete bibliographic information, a link to the original publication on https://www.jmir.org/, as well as this copyright and license information must be included. 